\section{AB1196 A STUDY REVIEWING THE ASSOCIATED FACTORS AND COST-EVALUATION OF SWITCHING BACK TO ORIGINATOR-ETANERCEPT FROM ITS BIOSIMILAR AMONG PATIENTS WITH RHEUMATIC DISORDERS AT A TERTIARY CARE CENTRE IN UNITED KINGDOM}

S. S. C. Silva ${ }^{1}$, B. Mahesh ${ }^{2}$, T. Rajakulenthiran ${ }^{3}$, R. Singh ${ }^{3}$, R. Amarasena ${ }^{3}$. ${ }^{1}$ The Robert Jones and Agnes Hunt Orthopaedic Hospital, Oswestry, United Kingdom; ${ }^{2}$ University of Melbourne, Population and Global Health Unit, Melbourne, Australia; ${ }^{1}$ The Robert Jones and Agnes Hunt Orthopaedic Hospital, Oswestry, United Kingdom

Background: Biological therapy plays a major role in the management of patients with rheumatic disorders. Evidences generated at experimental settings have shown biosimilars as clinically effective, safe and cost effective. Nevertheless, real world data are lacking about cost effectiveness and causes of switching back to originator product among patients

Objectives: To describe the associated factors and cost evaluation of switching back to the originator etanercept from the biosimilar among patients with rheumatic disorders at The Robert Jones and Agnes Hunt Orthopaedic Hospital of United Kingdom

Methods: A descriptive cross-sectional study was undertaken with secondary data in a tertiary care hospital. All the patients who were switched from original etanercept (originator) to biosimilar Etanercept from October 2018 to June 2019 were included in the study. A pre-tested data extraction sheet was used in the data collection. Annual expenditure estimates for the treatment modalities were collected by consulting the experts. Descriptive analysis was done for the characteristics of the study sample and for the estimated annual costs. Associations of age and sex in the switching of treatment modalities were explored with chisquare test and Mann Whitney $U$ test with $5 \%$ significance level.

Results: Records of 100 participants were extracted with a male to female ratio of 1: 1.4. The median [interquartile range (IQR)] of the participants was 54 (44 to 66 ) years. The leading three diagnoses were: rheumatoid arthritis $(65 \%)$, Ankylosing Spondylitis (18\%) and Psoriatic arthritis (14\%). Out of the participants, 32 $(32 \%)$ switched back to originator with a median (IQR) duration of 16.0 (10.5 to 19.5) weeks of commencing the biosimilar. The proportions of switching back were $28.1 \%, 34.4 \%$ and $37.5 \%$ among those who did, in the chronological $3-$ monthly intervals of the study. The main reasons for switching back included; side effects $(21.9 \%)$, lack of efficacy $(65.6 \%)$, both of these $(9.4 \%)$ and other reasons $(3.1 \%)$. Older age was observed among those who switched back $(p<0.05)$ but gender did not show a statistically significant association ( $p=0.532$ ). The annual estimated cost for biosimilar was $37.3 \%$ less than that for originator per patient. Conclusion: In our cohort nearly one third switched back to the originator following the commencement of biosimilar incurring a financial and resource burden to the rheumatology department which in turn will have wider ramifications on the health care system. Exploring the reasons and factors associated with switching back to the originator in larger scale studies would help in planning cost-effective interventions and understanding the reasons why the patients revert back to the originator from the biosimilar therapy, especially among the older patients.

References:

[1] Villamañan BE, Jiménez NI, Moreno RF, et al. AB1475-HPR Cost evolution of biological agents for the treatment of spondyloarthritis in a spanish tertiary hospital: influential factors in price development. Annals of the Rheumatic Diseases 2018, 77: p1867-1868. doi: 10.1136/annrheumdis-2018-eular.2681

[2] Brites L, Costa F, Freitas J, Luis M, Coutinho M, Santiago M, Duarte C, Salvador MJ, da Silva JAP. Impact of Block Switch to Biosimilar Etanercept in Practice, Accross Different Rheumatic Diseases [abstract]. Arthritis Rheumatol. 2018; 70 (suppl 10). Available at <https://acrabstracts.org/abstract/ impact-of-block-switch-to-biosimilar-etanercept-in-practice-accross-different-rheumatic-diseases>. Accessed [January 30, 2020].

Disclosure of Interests: None declared

DOI: 10.1136/annrheumdis-2020-eular.5761

\begin{tabular}{|l|l|}
\hline AB1197 & TREAT-TO-TARGET IS FEASIBLE IN RHEUMATOID \\
ARTHRITIS PATIENTS DURING PREGNANCY, FIRST \\
RESULTS OF THE PRECARA COHORT
\end{tabular}

H. T. Smeele ${ }^{1}$, E. Röder ${ }^{1}$, H. Wintjes ${ }^{1}$, L. J. Kranenburg - van Koppen ${ }^{1}$, J. Hazes ${ }^{1}$, R. Dolhain ${ }^{1} .{ }^{1}$ Erasmus MC, Rotterdam, Netherlands

Background: A treat-to-target approach results in better outcomes for Rheumatoid Arthritis (RA) patients [1]. Well controlled disease is important for pregnant RA patients and patients with a wish to conceive too. Not only for the welfare of the mother, but also because active disease is associated with a prolonged time to pregnancy and adverse pregnancy outcomes [2]. This is this first study to examine a treat-to-target approach during pregnancy

Objectives: To determine the feasibility of a treat-to-target approach in RA patients with a wish to conceive or pregnant.

Methods: Patients were derived from the PreCARA cohort (first inclusion 2011, data shown up to November 2019). The PreCARA cohort is an ongoing, single center, prospective study on RA and pregnancy. Patients in this cohort were treated according to a treat-to-target approach, in which the obvious restrictions of pregnancy were taken into account. Study visits were scheduled before, during and after pregnancy and disease activity (DAS28CRP) was measured. Results of the PreCARA study were compared with results of the PARA study [3], a historic reference cohort on RA during pregnancy, with a similar study design (inclusion $2002-2010$ ). Patients in the PARA cohort were treated according to the standards of that time. The PARA cohort represents the natural course of RA during pregnancy with limited treatment options. Results: 263 RA patients were included in the PreCARA cohort, up to now 154 children were born in this ongoing cohort. Mean age at inclusion was 32.3 (4.3 SD), $83.2 \%$ was Rheumatoid Factor positive and/or ACPA positive. Mean disease activity in the PreCARA cohort is statistically significant lower than in the PARA cohort at every time-point: mean DAS28CRP in $3^{\text {rd }}$ trimester in the PreCARA cohort 2.22 (0.73 SD), in the PARA cohort 3.35 (1.12 SD) P $<0.001$ (figure 1). In the PreCARA cohort $73.3 \%$ of the patients were in low disease activity or remission before pregnancy increasing to $90.4 \%$ in the third trimester, whereas in the PARA cohort these percentages were $32.2 \%$ and $47.3 \%$ respectively $(P<0.001)$ (figure 2$)$. Medication use in the PreCARA cohort is shown in table 1 and in the PARA cohort in table 2.

Table 1. Percentage of patients in the PreCARA cohort using certain medication $(n=154)$

\begin{tabular}{lcccccccc}
\hline Medication & $\begin{array}{c}\text { Before } \\
\text { pregnancy } \\
(\%)^{*}\end{array}$ & $\begin{array}{c}1^{\text {st }} \\
(\%)\end{array}$ & $\begin{array}{c}2^{\text {nd }} \\
(\%)\end{array}$ & $\begin{array}{c}3^{\text {rd }} \\
(\%)\end{array}$ & $\begin{array}{c}6 \text { weeks } \\
\text { post-par- } \\
\text { tum (\%) }\end{array}$ & $\begin{array}{c}12 \text { weeks } \\
\text { post-par- } \\
\text { tum (\%) }\end{array}$ & $\begin{array}{c}\text { post-par- } \\
\text { tum (\%) }\end{array}$ \\
\hline MTX & 5 & 0 & 0 & 0 & 15 & 19 & 15 \\
Leflunomide & 0 & 0 & 0 & 0 & 1 & 1 & 2 \\
Abatacept & 0 & 0 & 0 & 0 & 1 & 1 & 1 \\
Hydroxychloroqine & 63 & 51 & 51 & 50 & 49 & 43 & 31 \\
Sulfasalazine & 70 & 56 & 58 & 57 & 54 & 47 & 36 \\
Prednisone & 43 & 40 & 39 & 42 & 38 & 34 & 27 \\
Azathioprine & 1 & 2 & 1 & 1 & 0 & 1 & 1 \\
Certolizumab & 25 & 21 & 26 & 28 & 26 & 24 & 18 \\
Adalimumab & 10 & 5 & 0 & 0 & 3 & 3 & 4 \\
Infliximab & 5 & 8 & 3 & 0 & 1 & 1 & 1 \\
Etanercept & 13 & 10 & 9 & 3 & 10 & 11 & 9 \\
Golimumab & 0 & 0 & 0 & 0 & 0 & 0 & 1 \\
Tocilizumab & 3 & 1 & 0 & 0 & 3 & 2 & 3 \\
\hline
\end{tabular}

patients seen before pregnancy $=104$

Table 2. Percentage of patients in the PARA cohort, a reference cohort, using certain medication $(n=245)$. Medication that is not listed in this table was not prescribed in the study period.

\begin{tabular}{lccccccc}
\hline \multicolumn{1}{c}{ Medication } & $\begin{array}{c}\text { Before } \\
\text { pregnancy } \\
(\%)^{\star \star}\end{array}$ & $\begin{array}{c}1^{\text {st }} \\
\text { trimestertrimestertrimester } \\
(\%)\end{array}$ & $\begin{array}{c}2^{\text {nd }} \\
(\%)\end{array}$ & $\begin{array}{c}3^{\text {rd }} \\
(\%)\end{array}$ & $\begin{array}{c}6 \text { weeks } \\
\text { post-par- } \\
\text { tum }(\%)\end{array}$ & $\begin{array}{c}12 \text { weeks } \\
\text { post-par- } \\
\text { tum (\%) }\end{array}$ & $\begin{array}{c}\text { post-par- } \\
\text { tum }\end{array}$ \\
\hline MTX & 0 & 0 & 0 & 0 & 18 & 30 & 36 \\
Leflunomide & 0 & 0 & 0 & 0 & 0 & 1 & 2 \\
Hydroxychloroqine & 6 & 2 & 2 & 2 & 4 & 8 & 7 \\
Sulfasalazine & 34 & 25 & 27 & 26 & 26 & 30 & 29 \\
Prednisone & 42 & 33 & 36 & 36 & 35 & 36 & 32 \\
Azathioprine & 1 & 0 & 0 & 0 & 1 & 1 & 1 \\
Adalimumab & 0 & 0 & 0 & 0 & 2 & 3 & 5 \\
Infliximab & 0 & 0 & 0 & 0 & 0 & 1 & 1 \\
Etanercept & 0 & 0 & 0 & 0 & 3 & 6 & 5 \\
\hline
\end{tabular}

** patients seen before pregnancy $=124$

Conclusion: This first study on a treat-to-target approach in pregnant RA patients shows that low disease activity and remission are an attainable goal during pregnancy, with over $90 \%$ of patients achieving this in the $3^{\text {rd }}$ trimester. The effect of this approach on fertility and pregnancy outcomes should be the focus of further studies.

References:

[1] Smolen et al. Rheumatoid arthritis. Lancet 2016

[2] Smeele et al. Current perspectives on fertility, pregnancy and childbirth in patients with Rheumatoid Arthritis. Semin Arthritis Rheum 2019

[3] de Man et al. Measuring disease activity and functionality during pregnancy in patients with rheumatoid arthritis. A\&R 2007 